\title{
Evaluation of 1211 Third Molars Positions According to the Classification of Winter, Pell \& Gregory
}

\author{
Evaluación de Posiciones de 1211 Terceros Molares \\ Acorde a la Clasificación de Winter, Pell \& Gregory
}

\begin{abstract}
Fábio Tochetto Primo'; Bruno Tochetto Primo2; Miguel Angelo Ribeiro Scheffer²; Pedro Antonio González Hernández ${ }^{2} \&$ Elken Gomes Rivaldo ${ }^{3}$
\end{abstract}

PRIMO, F. T.; PRIMO, B. T.; SCHEFFER, M. A. R.; HERNÁNDEZ, P. A. G. \& RIVALDO, E. G. Evaluation of 1211 third molars positions according to the classification of Winter, Pell \& Gregory. Int. J. Odontostomat., 11(1):61-65, 2017.

ABSTRACT: Panoramic radiographs are important for the evaluation and classification of the third molars position, allowing the diagnosis and planning of extraction. The objective of this study is to evaluate upper and lower third molars positions in panoramic radiographs with the classification methods proposed by Pell and Gregory (1933) and Winter (1926) and the subsequent comparison of results with other authors. Panoramic radiographs of 310 patients were analyzed, 197 female and 113 male, totaling 1,211 third molars. In relation to the upper third molars, the most prevalent positions were: angle compared to the long axis of the second molar of Distoangular form (53.23\%) and the depth of impaction as Class C $(48.25 \%)$. In the lower third molars, the most prevalent positions were: angle to the long axis of the second molar in Mesioangular classification (52.96\%), the depth of impaction was B (46.54 \%) and the tooth relationship with the mandibular ramus was identified as class I ( $55.26 \%)$. These results provide information that can be utilized in predicting third molar development in terms of impaction or eruption, assisting dental surgeons in making decisions regarding surgical planning and treatment. evaluation.

KEY WORDS: dental extraction, third molar, impacted third molar, impaction, orthopantomogram, radiographic

\section{INTRODUCTION}

An impacted tooth is the enamel organ that even when fully developed, has not erupted into the oral cavity. The upper and lower third molars are the last teeth to erupt, the most affected by tooth impaction problems. The main factors related to the impaction of third molars are the lack of space, limited bone development, presence of adjacent teeth, dense bone structure or excess of soft tissue (Yilmaz et al., 2016).

The extraction of impacted third molars is intended to prevent the occurrence of pathologies as periodontal disease, dental caries, pericoronitis, odontogenic cysts and tumors, root resorption, mandible fracture, pain of unknown etiology and malocclusion (Polat et al., 2008). Radiographic evaluation of third molars is of fundamental importance to the establishment of therapeutic monitoring and surgical planning.

The primary determinant factor for removal difficulty is accessibility. This is determined by the adjacent tooth or other structures that are hindering the access or removal path, ease of tooth exposure, path preparation for removal, and preparation or use of the advantage of the pre-existing support point (Peterson, 1996). In order to identify the degree of accessibility, a classification for the impacted teeth was created. Winter classified the impacted teeth according to the angulation in: vertical, horizontal, mesioangular and distoangular. Pell \& Gregory (1933) classified the impacted teeth in relation to the occlusal plane of the second molar in: class $\mathrm{A}, \mathrm{B}$ and $\mathrm{C}$ and in relation to the

\footnotetext{
${ }^{1}$ Private Dental Clinic, Brazil.

2 Department of Oral and Maxillofacial Surgery, School of Dentistry, Universidade Luterana do Brasil (ULBRA), Brazil

${ }^{3}$ Department of Dental Prothesis, School of Dentistry, Universidade Luterana do Brasil (ULBRA), Brazil.
} 
anterior border of the mandibular ramus, in the case of the lower third molar, in classes I, II and III.

The objective of this study was to evaluate, through panoramic radiographs, the location and prevalence of upper and lower third molars, as classifications proposed by Winter and Pell \& Gregory.

\section{MATERIAL AND METHOD}

The analysis was performed by a surgeon dentist, specialist with a master's degree in Oral and Maxillofacial Surgery, using a negatoscope, of panoramic radiographs of 310 patients referred for extraction surgery of third molars, without registration in the medical record for the extraction of the third molars, chosen randomly from the Centro de Ensino e Tratamento Odontológico Chapecó S/a - Santa Catarina, Brazil. The collected data were the gender, age and the classification of third molars with the presence of at least one third of root canal, according to the criteria of Pell \& Gregory, and Winter. Data were tabulated using Microsoft Excel (Microsoft Corporation, USA).

The teeth were classified according to Pell \& Gregory: depth of impaction: Position A - the occlusal plane of the third molar is above or at the level of the occlusal plane of the second molar; Position B - the occlusal plane of the third molar lies between the cervical line and the occlusal plane of the second molar; Position $\mathrm{C}$ - the occlusal plane of the third molar lies below the cervical line of the second molar. Tooth relationship with the mandibular ramus: Class I - the distance between the distal surface of the second molar and the mandibular ramus is larger than the mesiodistal diameter of the third molar; Class II - the distance between the distal surface of the second molar and the ramus is smaller than the mesiodistal diameter of the third molar; Class III - there is no space between the distal surface of the second molar and the mandibular ramus.

Angulation (Winter): Vertical - the long axis of the third molar is parallel to the long axis of the second molar; Horizontal - the long axis of the third molar is perpendicular to the long axis of the second molar; Mesioangular - the long axis of the tooth is inclined towards the second molar; Distoangular - the long axis of the third molar is angled distally or tilted backwards to the long axis of the second molar.

\section{RESULTS}

Panoramic radiographs of 310 patients analyzed were assessed; 197 were female and 113 male. In total, 1211 third molars of patients with an average age of 17 were evaluated. The highest age was 35 and the lowest was 14. Concerning the upper third molars, 603 were present and 17 absent; from the lower third molars, 608 were present and 12 absent. For the total number of the 603 upper third molars, the prevailing data was: dominance of distoangular position (53.23 $\%$ ), followed by the vertical angulation (32.50 \%) (Fig, $1)$. In the evaluation, regarding the classification of Pell \& Gregory, the prevalence of upper third molars related to depth impaction was C $(48.25 \%)$, followed by $B$ $(33.16 \%)$ (Fig. 2).

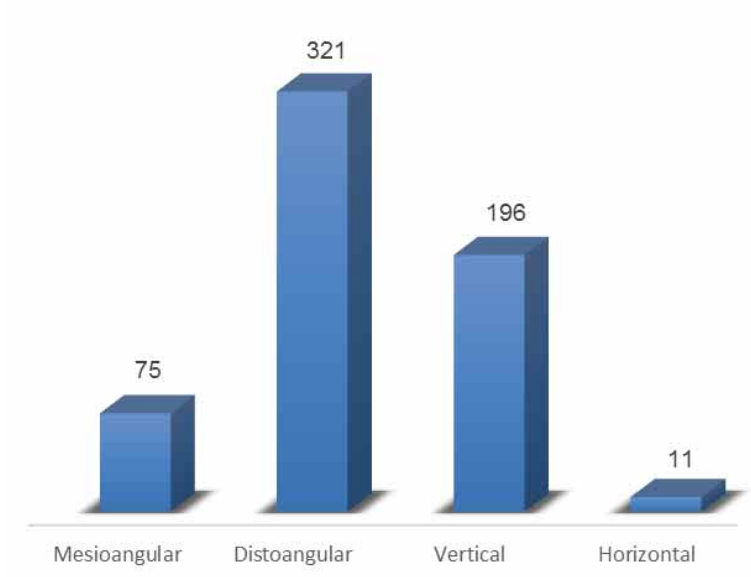

Fig. 1. Angulation of the upper third molars; Distribution of upper third molars according to the angulation.

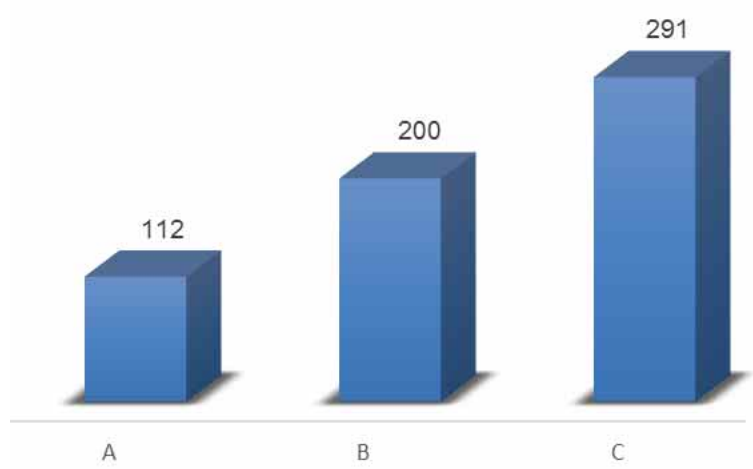

Fig. 2. Impaction depth of the upper third molars; distribution of the upper third molars according to the depth of impaction. 
For the lower third molars, the prevalence was of mesioangular position (52.96 \%), followed by the vertical position (39.14\%) (Fig. 3). Evaluating the depth, the predominant one was B (46.54\%), followed by A (39.63\%) (Fig. 4). The prevalence of the tooth relation to the mandibular ramus was class I (55.26 $\%$ ), followed by class II (25.65 \%) (Fig. 5).

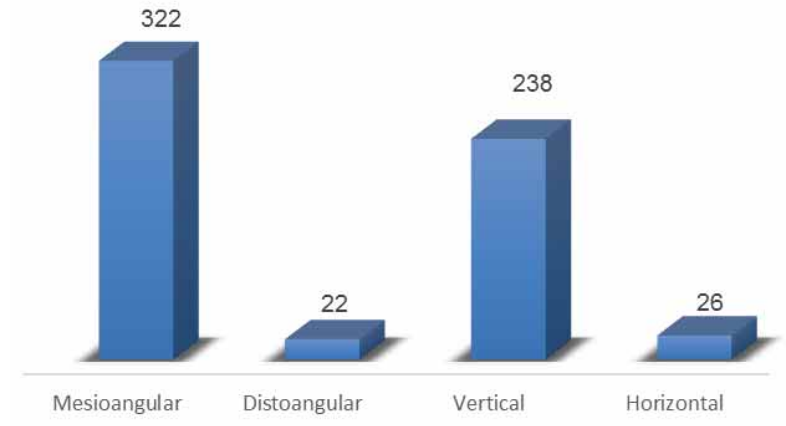

Fig 3. Angulation of the lower third molars; Distribution of lower third molars according to the angulation.

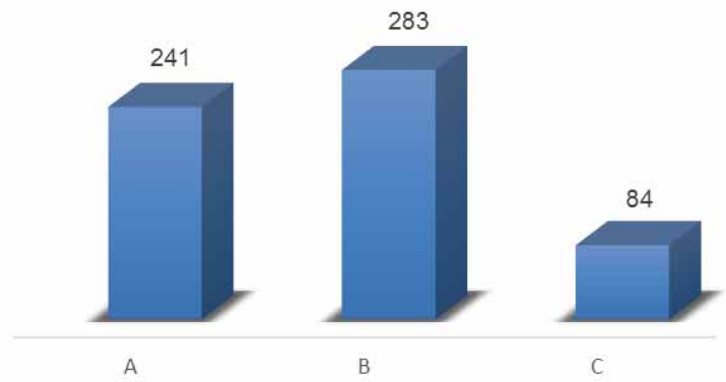

Fig. 4. Impaction depth of the lower third molars; Distribution of lower third molars according to the depth of impaction.

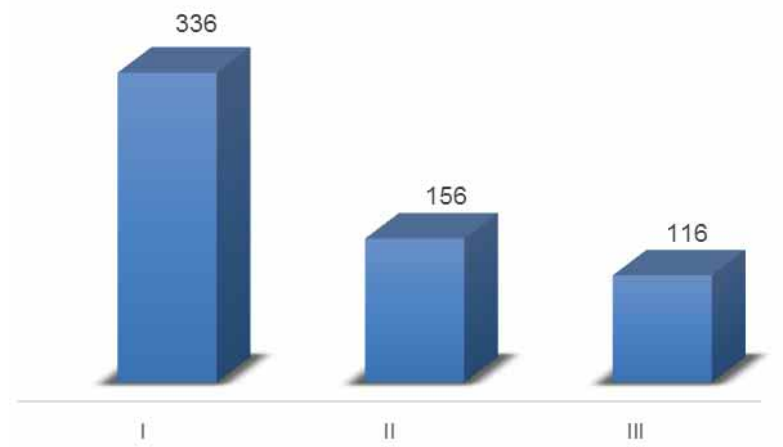

Fig. 5. Class of lower third molars. Distribution of lower third molars according to the relation to the anterior border of the mandible.

\section{DISCUSSION}

The analysis of impaction of third molars is important for evaluating the risk of developing pathologies, surgical treatment plan definition and possible surgical complications, thus justifying the necessity for this study.

Impacted teeth may cause pain, food impaction, inflammation and infection. For the evaluation of impacted third molars, radiographs are still the standard. Panoramic radiographs are used to evaluate the type of impaction, anatomical structures that are preventing the eruption, if the tooth is fully or partially inside the bone, basal bone height, the condition of second molars and the relation of the third molars to the inferior alveolar canal; so that the extraction can be adequately planned (Kumar-Pillai et al., 2014).

Hashemipour et al. (2013) showed in a study that mesioangular and horizontal angulation of impaction were the most common in the mandible. The most common type of impaction, according to the Pell \& Gregory rating was IIA. The most common angle in the maxilla was the vertical angle, different from ours, in which the distoangular position was the most prevalent, and also different from the study by Kruger et al. (2001), which concluded that mesioangular impaction was the most observed pattern of the upper arch impaction.

In the study by Kumar-Pillai et al., in Indian people with 2210 impacted third molars, the highest frequency of impaction was in the vertical position (46.6\%), followed by mesioangular (28.5\%), horizontal (16.7\%) and distoangular (7.69 \%). Yilmaz et al., aiming at evaluating the pattern of third molar impaction and symptoms associated in a Turkish population, examined patients with an average age of 30.58 years, with 2133 impacted third molars of 705 panoramic radiographs; the most common impaction angulation in both jaws was vertical $(1177 ; 55 \%)$. Level B of impaction was the most common in the maxilla (425/1037 39\%), while the level $\mathrm{C}$ of impaction was the most common in the mandible (635/1096; $61 \%)$. The results diverge from the work presented here, in which the $C$ level of impaction was most frequently found in the maxilla and the level $B$ in the mandible, as well as the angulation of the third molar in the maxilla prevailed in most as distoangular and in the mandible as mesioangular. Pain (272/705; $39 \%)$ and pericoronitis $(188 / 705,27 \%)$ were the most common complications of impaction. Among 705 patients (335 men, 370 women), pericoronitis was more 
prevalent in males $(101 ; 30 \%)$ and generally related to lower third molars (236; $22 \%$ ) and was more closely associated to third molars with vertical angulation. As noted by Leone et al. (1986), who reported that the kind of third molars that were more likely to cause pericoronitis were in the vertical angle and distoangular.

Obiechina et al. (2001) assessed the level of impaction according to Pell \& Gregory and showed that $358(54.55 \%)$ third molars were in position A, 151 (31.92 $\%)$ were in position $B$, and $64(13,53 \%)$ were in position C. One hundred seven $(22.62 \%)$ were in position I, 288 $(60.89 \%)$ were in position II, and $78(16.49 \%)$ were in position III. From the 473 impacted third molars, 323 $(68.29 \%)$ had symptoms of pain. Two hundred and seventy-two (57.51\%) impacted teeth were associated with pathology. Of these, $203(42.92 \%)$ were pericoronitis and periodontal disease, 66 (13.95\%) were caries, while $3(0.63 \%)$ were associated with cysts. The study by Inaoka et al., (2009) assessed the relationship between third molars and mandibular angle fractures. The results showed an increased risk of angle fractures when the third molar is present, especially when positioned on class I and II, A and B of the Pell \& Gregory classification.

Torres et al. (2008) and Inaoka et al., indicate the vertical position as the most common in lower third molars, followed by mesioangular position. Hassan (2010), in a study with a total of 228 third molars in the maxilla, obtained the vertical angulation as the most prevalent and a depth of impaction of class B, different from our study. For 349 mandible third molars, the highest prevalence was mesioangular angle, equal to our study. These differences in results regarding the classification of third molars may be related to the stage of root formation, when the teeth were analyzed. In the present study, it was adopted as a criterion the presence of at least one third of root formation, for this is the right time for extraction.

The prevalence and types of tooth impaction may vary in different racial and ethnic groups. These may be due to racial genetic characteristics, endogamy, as well as epigenetic factors such as eating habits. Therefore, it is important to understand the pattern of impaction in various communities and population sub-groups (KumarPillai et al.).

In the study by Torres et al. the vertical position predominated among third molars with associated pathology. Polat et al. determined the association between pathological conditions commonly found and depth and angulation of impacted lower third molars (ILTM) analyzing 1,914 panoramic radiographs with 3050 teeth. The problems and prevalence were observed: caries in the second lower molar (12.6\%), caries on ILTM (5.3\%), bone loss on the distal surface of ILTM $(9.7 \%)$, and damage to the periodontal tissue in the adjacent teeth $(8.9 \%)$. A total of $26.5 \%$ of all cases were affected by any of the four pathological changes. It was determined that the horizontal and mesioangular ILTM had high risk of caries development in the second or third molar; in contrast, vertical and distoangular ILTM had low risk. Distoangular and vertical ILTM had high risk of developing loss of bone in the distal surface. Mesioangular and horizontal ILTM had a high risk of damage to periodontal tissues in an adjacent tooth. When evaluating the depth of impaction of the ILTM class A, it was found that they had a higher risk of disease than class $B$ or $C$. The results justify the prophylactic removal of impacted third molars.

In the research of Torres et al., the main indication of third molar extraction was the prevention of diseases, followed by orthodontic reasons. Regarding third molars with symptoms or clinical signs associated, infectious diseases - including pericoronitis - were the most frequently observed pathologies, followed by caries.

The following indications for third molar extraction were highlighted by Koerner (1994) and Santosh (2015): associated pathology or pain due to pericoronitis, periodontitis, periapical abscesses, cysts or tumors, resorption of the adjacent roots, inflammation of the soft adjacent tissue; situations in which the tooth is facing buccal or lingual positions; discrepancy in the length of the arch in cases when the impacted third molars are affecting the stability of the orthodontic treatment. Lytle (1995) added infection around the impaction, loss of bone around the impacted teeth; tooth decay and damage to adjacent teeth; and extraction of impacted teeth before the root formation.

The classification carried out in this study may help in surgical planning so that it is possible to reduce the possibility of complications related to third molar extractions that can be trans-operative and postoperative. Trans-operative complications are the following: mandibular fractures, damage to adjacent teeth, tooth fragments or teeth displacement to adjacent anatomical spaces and hemorrhage (Santosh; Susarla et al., 2003). In cases where intraoral excessive force is applied and large bone removal maneuvers are performed, the risk of mandibular fracture or damage to adjacent teeth is increased, and it is worth noting in the classification B and $\mathrm{C}$ for the lower third molars. Typical postoperative complications are pain, swelling, inflammation, trismus, osteitis and surgical site infection (Bouloux et al., 2007). 
In conclusion, it is expected that the results of this study, in addition to studies obtained in the specialized literature reported here, provide information that can be used in the evaluation of third molars and assist surgeon dentists in making decisions with regard to surgical planning and treatment.

PRIMO, F. T.; PRIMO, B. T.; SCHEFFER, M. A. R.; HERNÁNDEZ, P. A. G. \& RIVALDO, E. G. Evaluación de posiciones de 1211 terceros molares acorde a la clasificación de Winter, Pell \& Gregory. Int. J. Odontostomat., 11(1):61-65, 2017.

RESUMEN: Las radiografías panorámicas son importantes para la evaluación y clasificación de la posición de los terceros molares, lo que permite el diagnóstico y la planificación de la extracción. El objetivo de este estudio fue evaluar terceros molares superiores e inferiores y posiciones en las radiografías panorámicas con los métodos de clasificación propuestas por Pell \& Gregory, y Winter y la posterior comparación de los resultados con otros autores. Se analizaron las radiografías panorámicas de 310 pacientes, 197 mujeres y 113 hombres, con un total de 1.211 terceros molares. En relación con los terceros molares superiores, las posiciones más prevalentes fueron: ángulo con respecto al eje longitudinal del segundo molar de forma distoangular (53,23 \%) y la profundidad de la impactación como Clase C (48,25\%). En los terceros molares inferiores, las posiciones más prevalentes fueron: ángulo con respecto al eje longitudinal del segundo molar en la clasificación mesioangular $(52,96 \%)$, la profundidad de impactación fue de B $(46,54 \%)$ y la relación de los dientes con la rama mandibular fue identificado como Clase I $(55,26 \%)$. Estos resultados proporcionan información que puede ser utilizada para predecir el desarrollo del tercer molar en términos de compactación o erupción, ayudando a los cirujanos dentistas en la toma de decisiones respecto a la planificación y el tratamiento quirúrgico. radiográfica.

PALABRAS CLAVE: extracción dental, tercer molar. tercer molar impactado. impactación. ortopantomografía, evaluación

\section{REFERENCES}

Bouloux, G. F.; Steed, M. B. \& Perciaccante, V. J. Complications of third molar surgery. Oral Maxillofac. Surg. Clin. North. Am., 19(1):11728, 2007.

Hashemipour, M. A.; Tahmasbi-Arashlow, M. \& Fahimi-Hanzaei, F. Incidence of impacted mandibular and maxillary third molars: a radiographic study in a Southeast Iran population. Med. Oral Patol. Oral Cir. Bucal., 18(1):140-5, 2013.

Hassan, A. H. Pattern of third molar impaction in a Saudi population. Clin. Cosmet. Investig. Dent., 11(2):109-13, 2010.

Inaoka, S D.; Carneiro, S.; Vasconcelos, B.; Leal, J. \& Porto, G. G. Relationship between mandibular fracture and impacted lower third molar. Med., Oral Patol. Oral Cir. Bucal, 14(7):349-54, 2009.

Koerner, K. R. The removal of impacted third molars. Principles and procedures. Dent. Clin. North Am., 38(2):255-78, 1994.

Kruger, E.; Thomson, W. M. \& Konthasinghe, P. Third molar outcomes from age 18 to 26: findings from a population-based New Zealand longitudinal study. Oral Surg. Oral Med. Oral Pathol. Oral Radiol. Endod., 92(2): 150-5, 2001.

Kumar-Pillai, A.; Thomas, S.; Paul, G.; Singh, S. K. \& Moghe, S. Incidence of impacted third molars: A radiographic study in People's Hospital, Bhopal, India. J. Oral Biol. Craniofac. Res., 4(2):76-81, 2014.

Leone, S. A.; Edenfield, M. J. \& Cohen, M. E. Correlation of acute pericoronitis and the position of the mandibular third molar. Oral Surg. Oral Med. Oral Pathol. Oral Radiol., 62(3):245-50, 1986.

Lytle, J. J. Etiology and indications for the management of impacted teeth. Northwest Dent., 74(6):23-32, 1995.

Obiechina, A. E.; Arotiba, J. T. \& Fasola, A. O. Third molar impaction: evaluation of the symptoms and pattern of impaction of mandibular third molar teeth in Nigerians. Odontostomatol. Trop., 24(93):22-5, 2001.

Pell, G. J. \& Gregory, B. T. Impacted mandibular third molars: Classification and Impacted mandibular third molars: Classification and modified technique for removal. Dent. Digest., 39:330-8,1933.

Peterson, L. J. Principles of Management of Impacted Teeth. In: Peterson, L. J.; Ellis, E. III; Hupp, J. R. \& Tuker, M. R. (Ed.). Contemporary Oral and Maxillofacial Surgery. $3^{\text {rd }}$ ed. St. Louis, Mosby, 1998.
Polat, H. B.; Ozan, F.; Kara, I.; Ozdemir, H. \& Ay, S. Prevalence of commonly found pathoses associated with mandibular impacted third molars based on panoramic radiographs in a Turkish population. Oral Surg. Oral Med. Oral Pathol. Oral Radiol., 105(6):41-7, 2008.

Santosh, P. Impacted mandibular third molars: Review of literature and a proposal of a combined clinical and radiological classification. Ann. Med. Health Sci. Res., 5(4):229-34, 2015.

Susarla, S. M.; Blaeser, B. F. \& Magalnick, D. Third molar surgery and associated complications. Oral Maxillofac. Surg. Clin. North. Am., 15(2):177-86, 2003.

Torres, M. A. F.; Albiol, J. G.; Aytes, L. B. \& Escoda, C. G. Evaluation of the indication for surgical extraction of third molars according to the oral surgeon and the primary care dentist. Med. Oral Patol. Oral Cir. Bucal, 13(8):499-504, 2008.

Winter, G. B. Impacted Mandibular Third Molar. St. Louis, American Medical Book, 1926.

Yilmaz, S.; Adisen, M. Z.; Misirlioglu, M. \& Yorubulut, S. Assessment of third molar impaction pattern and associated clinical symptoms in a central anatolian turkish population. Med. Princ. Pract., 25(2):16975, 2016.

Correspondence to:

Dr. Fábio Tochetto Primo

Rua Barão do Rio Branco 430-E - Sala 18

Chapecó, Santa Catarina

BRAZIL

E-mail: fabiotprimo@gmail.com

Received: 25-08-2016

Accepted: 23-12-2016 